\title{
MANUEL GARCÍA. HERENCIA VOCAL. PRESENTE Y FUTURO
}

\author{
Emilio Bayón \\ Universidad de Música Federico Chopin \\ https://doi.org/10.18778/8220-195-6.35
}

\section{Resumen}

Manuel García representa el corazón de los cantantes de Bel Canto con la magnificencia de sus habilidades vocales, las cuales trató de infundir tanto en sus textos y en sus hijos -María Malibrán, Pauline Viardot y Manuel Patricio García- como también en sus alumnos. A través de datos históricos y un profundo y vasto análisis de los textos anteriores a García, mostraré como el aspecto mecánico de la técnica vocal llega hasta Manuel García proveniente de los castrados españoles incluso antes de la creación de la ópera.

Palabras clave: Manuel García, castrados, bel canto, entrenamiento vocal, técnica vocal.

Manuel García (1775-1832) y sus hijos fueron los intérpretes con mayor éxito de Bel Canto en su tiempo; una forma de cantar que, incluso en nuestros días, no se ha podido superar; con poderosos instrumentos, gran extensión y flexibilidad. El objeto de esta propuesta es encontrar el origen de dichas destrezas para reconquistar ese conocimiento dando la posibilidad a estudiantes y profesionales de acercarse a la autentica técnica vocal del llamado Bel Canto.

El primer acercamiento para localizar el origen de cómo García cantaba reside, por una parte, en sus profesores, y por la otra, analizando y cotejando los ejercicios vocales escritos por sus predecesores en los pocos textos que han subsistido hasta nuestros días. 
Anzani, el último de los hijos de la gran escuela que brilló tan vivamente en los siglos XVII y XVIII; Anzani, cuya presencia atemorizaba a los más famosos castrati, afectuosamente acogió a García y le reveló los secretos de esa enseñanza que durante tanto tiempo fueron la gloria de Italia. (Radomski, 2000: 289)

La primera conexión es Giovanni Anzani/Ansani (1744-1826) y seguida inmediatamente en su mentor, que no es otro que Niccolò Porpora (1686-1768), uno de los más grandes profesores de canto en Italia. "Ansani ha sido pupilo del celebrado profesor y compositor Niccolò Porpora, con lo que es posible que el joven Manuel recibiese una temprana iniciación dentro de la antigua tradición de canto italiano" (Stark, 1999: 4). En estos textos encontramos una información significativa sobre el tipo de instrucción que recibió García. Porpora fue profesor en el Conservatorio de La Pietà en Nápoles. Nápoles era territorio español en esa época, y uno de los epicentros de los primeros castrados.

El canto de los castrados, que había sido conocido en el Imperio Bizantino, posiblemente entró en Europa durante el reino Morisco en Al Ándalus y, desde aquí, se extendió hasta Italia a mediados del siglo XVI. Por un lado, la ley canónica cristiana prohibió la castración bajo pena de excomunión. Por otro lado, hubo una demanda constante de voces agudas para cantar en la iglesia. Las mujeres tenían prohibido actuar públicamente, al menos en los Estados Papales, hasta bien entrado el siglo XIX. El resultado fue que la castración se practicase en secreto.

(Mieszkowski, 2014: 84-85)

Los eunucos habían sido utilizados constantemente no solo en harenes desde los primeros tiempos de Constantinopla (Imperio Bizantino), sino también como oficiales. Y, desde el siglo XII, en los coros dominantes de la Iglesia Occidental.

"Fuentes rusas registran que castrados, incluido un eunuco griego llamado Manuil (o Manuel), llegaron a Smolensk en 1137” (Remondino, 1891: 94). 
Desde la ocupación Morisca ha habido eunucos en España:

[...] un método especial de producir la voz en un falseto más poderoso fue supuestamente desarrollado en España durante el siglo XVI, y el coro papal importaba la mayor parte de estos cantantes (spagnoletti) [...]. Estas voces agudas eran probablemente castrados encubiertos. El último falsetista, Giovanni de Sanctis de Toledo, cantó en el coro de la Sixtina desde 1588 hasta 1625. Los primeros castrados italianos, Petrus Paulus Folignatus y Hieronimus Rossinus fueron admitidos en el coro papal en 1599. (Marek, 2016: 4)

"Parece lógico que la influencia Morisca en España pudo posiblemente jugar un papel en el llamado «Secreto español del falseto" y que los falsetistas españoles eran realmente castrados encubiertos, que evitaron la censura de su desafortunada condición" (Marek, 2007: 11).

Y aun antes "el 7 de abril de 1563 se produce el regreso de Giovanni Figueroa, «Eunuco» y llamado Giacomo Spagnoletto, y desde 1588 primer soprano italiano" (Cappelletto, 1995: XII). Difícil es que un hombre con el apellido Figueroa y llamado Spagnoletto fuese italiano; pero continuando en esta línea, "el primer cantor castrado invitado en la Capilla Sixtina es el español Francisco Soto de Langa en 1562, mientras que el primer italiano es Giacomo Spagnoletto en 1588" (Rendina, 2009: ebook).

Francisco Soto de Langa nació hacia 1534 en Langa de Duero, provincia de Soria. Se trasladó a Roma donde cantó en el coro de la Capilla Sixtina desde 1562 hasta su fallecimiento en 1619 a la edad de 85-86 años. Trabajó para el Oratorio de San Felipe Neri desde 1566 con cuyo fundador mantuvo una profunda amistad. Y siendo un castrado, en 1575 fue ordenado sacerdote. Francisco tuvo mucho éxito en Italia como cantor, alabado incluso por Pietro della Valle (1586-1652). Aún se conservan composiciones suyas.

Los castrados españoles dominaban sobre los castrados de otros países incluyendo Italia, como describe Rambotti: "el desorden comienza por los Liberati en 1601 cuando el castrado 
Girolamo Rosini Perugini (1581-1644) es admitido en la Capilla Pontificia. Con este episodio se abre el camino para la utilización de los castrados italianos que reemplazarán gradualmente a los españoles (Rambotti, 2008: 21-22). Y Arteaga asegura que

Flamencos y franceses fueron buscados de las cortes italianas, pero también los españoles, y gran reputación consiguieron estos con los Papas y gran autoridad tuvieron en la Capilla Pontificia, los sopranos de la cual en tiempos de Girolamo Rosini Perugino todos eran españoles, según cuenta el italiano Andrea Bolsena en las observaciones para afinar el canto en la Capilla Pontificia. (Arteaga, 1783: 161).

Se estima que más de 4.000 niños fueron castrados anualmente al servicio de este arte. Muchos provenientes de familias pobres con la esperanza en el éxito del niño pudiese sacarlos de su situación como es el caso de Giusto Fernando Teducci, llamado Il Senesino (c. 1756-1790). También existen registros de jóvenes que voluntariamente solicitaron la operación para preservar sus voces como Gaetano Majorano, llamado Caffarelli (1710-1783).

En Timoteo 2:11-12 se puede leer: "La mujer aprenda en silencio, con toda sujeción. Porque no permito a la mujer enseñar, ni ejercer dominio sobre el hombre, sino estar en silencio". Asimismo, en Corintios 14:34-35: "vuestras mujeres callen en las congregaciones; porque no les es permitido hablar, sino que estén sujetas, como también la ley lo dice. Y si quieren aprender algo, pregunten en casa a sus maridos; porque es indecoroso que una mujer hable en la congregación". A consecuencia de estos pasajes de la Biblia, con el Papa Sixto V (1521-1590), puesto que mantuvo entre 1585 y 1590 , encontramos:

El uso de sopranos masculinos conocidos como musici ya era común en la Iglesia en 1588, cuando el Papa Sixtus V expulsó a las mujeres de los escenarios en los Estados Papales; la prohibición, levantada en 1590, fue reimpuesta por Inocente XI en 1676 y persistió con interrupciones hasta comienzos del siglo XVIII. (Senelick, 2000: 193) 
En 1562 los castrados españoles comienzan a llegar a Italia (parcialmente territorio español) y son contratados por el Papa para interpretar música en la Capilla Sixtina. Desde 1588 la iglesia prohíbe a las mujeres tanto hablar como cantar en las iglesias y en las escenas. "En 1637 [...] la ópera L’Andromeda se estrenaba en el primer teatro de ópera inaugurado en Italia. Por primera vez en la historia, cualquier persona capaz de pagar el precio de la entrada podía presenciar el espectáculo" (Menéndez Torrellas, 2013: 33). Con la comercialización de este reciente género a comienzos del siglo XVII, los empresarios abaratan costes reduciendo las orquestas, coros y números de ballet, siendo los castrados quienes, con sus acrobacias vocales, atraen al público. Hasta mediados del siglo XVII los castrados españoles dominan el arte del canto y es sólo en este momento que los castrados italianos comienzan a sustituir a los españoles, con lo que resulta lógico deducir que son los castrados españoles quienes establecen la escuela vocal italiana.

En el transcurso de esta investigación he realizado varias genealogías desde y hasta las personas mencionadas y otras importantes personalidades de la época. Siendo un trabajo arduo y estimulante al ir apareciendo multitud de músicos. Como ejemplos: Francesco Durante (1684-1755) considerado el fundador de la escuela napolitana fue alumno de Bernardo Pasquini (1637-1710) que a su vez estudió con el castrado Loreto Vittori (1604-1670) que fue alumno de Francisco Soto de Langa (1534-1619), el primer castrado en ser admitido en la Capilla Sixtina. Uno de los alumnos de Francesco Durante (1684-1755) fue Fedele Fenaroli (1730-1818). Fenaroli tuvo entre sus alumnos por una parte a Francesco Ruggi (1767-1845) que fue preceptor de Vincenzo Bellini (1801-1835); y por otra parte a Vincenzo Lavigna (1776-1836), maestro de Giuseppe Verdi (1813-1901).

Desde otro de los grandes castrados, Giuseppe Santarelli (1710-1790) encontramos entre sus discípulos al pianista y compositor Muzio Clementi (1752-1832) que cantó en su infancia en el coro papal y a su alumno Carl Czerny (1791-1857) que al igual que su maestro fue niño cantor en la Capilla Sixtina y teniendo como discípulo al gran Franz Liszt (1811-1886). 
El gran descubrimiento en estas genealogías se encuentra en los castrados repartidos por todos los ámbitos musicales. Todos ellos fueron maestros de grandes músicos, no sólo cantantes sino también directores de orquesta, pianistas, compositores, etc. Tuvieron gran influencia en la música y los músicos desde el siglo XVI hasta mediados del siglo XIX. Sus conocimientos se extienden hasta el siglo XX. Como ejemplo una cantante fallecida, pero de todos conocida: María Callas (1923-1977), alumna de la gran Elvira de Hidalgo (1892-1980) que fue pupila del tenor español Melchor Vidal. Desgraciadamente no existe mucha información respecto a este último, pero si se sabe que cantó junto a Isabel Colbrand (1785-1845), esposa de Gioacchino Rossini (1792-1868). Se dice de este tenor ser el continuador de la técnica de Manuel García.

María Callas es el ejemplo más reciente y próximo a Pauline Viardot-García (1821-1910). Una considerada soprano, la otra mezzo. Ambas interpretaron papeles similares. Ambas poseían un registro vocal inmenso que muy pocas mujeres han logrado. Ambas han tenido un entrenamiento vocal similar, si bien el de Pauline probablemente resultó más duro. Se ha llegado a decir de María que ella misma destruyó su voz al interpretar papeles tan dispares como Lohengrin de Richard Wagner (1813-1883) e I Puritani de Vincenzo Bellini (1801-1835) en un muy corto plazo de tiempo. Ahora sabemos que fueron otras cuestiones las que provocaron su deterioro. Pauline al igual que María interpretó a Wagner y a Bellini en un corto plazo de tiempo sin ninguna dificultad. Es decir, el entrenamiento vocal sistematizado de Manuel García proveniente del trabajo mecánico diario de los castrados es lo que permite generar estas grandes voces capaces de las mayores proezas vocales.

Hemos de averiguar por tanto en qué consiste esta práctica utilizada por los castrados y si es realmente la base de los escritos de Manuel García. Sabemos que su formación era extremadamente rigurosa: una hora de estudio de pasajes difíciles e incómodos, una hora practicando trinos, una hora de pasajes con ornamentación, una hora cantando los ejercicios en presencia de un preceptor frente a un espejo para evitar movimientos faciales 
innecesarios y una hora más de estudio de literatura; todo esto antes del almuerzo. Además de otros estudios de teoría, contrapunto y composición.

Debido a los altos costes en impresión de textos, resulta complejo encontrar escritos de la época de los primeros castrados. Entre los primeros tratados sobre técnica vocal se encuentran Conforti de 1592, Carissimi de 1692 y Mancini de 1777 por poner unos ejemplos. No todos contienen ejercicios vocales técnicos escritos y las explicaciones son exiguas, pero entre los tratados que los incluyen, todos comparten elementos en común: notas largas, giros, trinos, escalas, etc. Las llamadas notas largas o sostenidas se utilizan tanto en instrumentos de viento como en instrumentos de cuerda. En el caso de las voces existen dichas notas de larga duración, aunque no siempre se menciona, como 'messa di voce' - cantar un sonido de larga duración comenzando en la dinámica más débil haciéndola crecer en fuerza para regresar a la dinámica de partida. En los instrumentos de cuerda se utilizan las notas de mayor duración como un trabajo del arco para conseguir una igualdad en la producción del sonido. En los instrumentos de viento y en la voz tiene la misma correspondencia con el aire y el apoyo. Los intervalos (distancia entre dos sonidos), que dependiendo de su extensión podemos llamar saltos, también contienen una dificultad técnica en todos los instrumentos. Las escalas y los arpegios (sucesión de notas consecutivas y alternas, en sentido ascendente y/o descendente) tienen usos diferentes en distintos instrumentos siendo algunos de ellos: entonación y coordinación. En la voz, el uso de escalas y arpegios incluye un trabajo en flexibilidad y extensión del registro. Existen distintas escalas con multitud de variaciones de objetivos similares a los anteriores, aunque de mayor complejidad, pero en los ejercicios vocales actuales la variedad de escalas es mínima. Algo similar se puede decir del ataque sobre una sola nota, muy utilizado en el barroco por clavecinistas como Domenico Scarlatti (1685-1757) o Antonio Soler (1729-1783). En la voz resulta particularmente complicado atacar una misma nota consecutivamente evitando forzar las cuerdas vocales. Los giros (sucesión de notas próximas entre sí en combinación múltiple) en los instrumentos de cuerda suponen un reto 
digital y de manejo de arco además de coordinación, con un objetivo similar aplicado a la voz, siendo algunos de ellos de gran dificultad técnica. Igualmente, los trinos (sucesión rápida de dos sonidos a distancia de tono o semitono) son particularmente difíciles de ejecutar con la voz sin agotar el instrumento y utilizando el aire apropiadamente. Los cromatismos (sucesión de notas a distancia de semitono) debido a su vecinidad interválica suponen también un reto técnico que necesita un trabajo diario y correcto para su apropiada ejecución.

Pauline Viardot escribió Una hora de estudio, un libro con ejercicios vocales, cuyo epígrafe ya conlleva implícito algún tipo de trabajo mecánico diario; y conociendo el tipo de trabajo de sus antecedentes castrados (recordemos que tenían cinco horas de trabajo -en su mayoría vocal- antes del almuerzo) podemos asumir que dichos ejercicios no eran completamente su invención (acaso fueron personalizados), sino que se refieren a una práctica que ella consideraba necesaria para el desarrollo vocal, y más concretamente el suyo propio. Manuel Patricio García (1805-1906), hijo varón de Manuel García, también dejó por escrito multitud de información útil, no sólo en técnica vocal, sino también sobre la fisiología de la voz, ambos con resonancias paternas. Los textos de Manuel García son una compilación, clasificación, sistematización y explicación completa de todos los problemas técnico-vocales y las herramientas necesarias para la superación de dichas dificultades, pero con explicaciones en extremo breves o sin instrucción alguna; siendo utilizados por toda la familia García con resultados que pudieron ser escuchados en todo el mundo y donde encontramos registros en todas las críticas de sus actuaciones.

La parte mecánica de la voz como un instrumento fue habitual desde los tiempos de los primeros castrados sobreviviendo hasta la mitad del siglo XIX, cuando los profesores ya empezaban a preguntarse donde estaban esos grandes cantantes con fuerza, agilidad, brillantez... La respuesta a esta pregunta constituye el tema principal de otro estudio que podría ser publicado prestamente. Habiendo analizado concienzudamente muchos de estos tratados con ejercicios vocales, y usándolos parcialmente como base -ya 
que hay otros elementos como fundamento de estas afirmaciones-, he creado un sistema de ejercicios observando las dificultades técnico-vocales siendo aún imposible afirmar su efectividad; sin embargo sí puedo informar (ya que varios cantantes profesionales están utilizando este sistema en este momento) que los resultados son, cuanto menos, alentadores; de hecho, la totalidad de las personas que emplean estos ejercicios mecánicos diarios (independientemente de sus propios ejercicios de calentamiento vocal) reportan grandes avances.

Para concluir y respondiendo a un profesor que recientemente me cuestionó: ¿qué falta en la técnica vocal actual?, puedo afirmar que el área mecánica en la práctica diaria es lo que se ha extinguido en la educación vocal actual y se puede recuperar. Los castrados la utilizaron y es de todos conocido el resultado, e igualmente se sabe que este tipo de entrenamiento vocal fue el utilizado por los más grandes cantantes durante el periodo conocido como Bel Canto.

\section{Bibliografía}

Arteaga, S. (1783). Le rivoluzioni del TEATRO MUSICALE ITALIANO dalla sua origine fino al presente, Bologna: Carlo Trenti.

Cappelletto, S. (1995). La voce perduta: vita di Farinelli, evirato cantore, Torino: E.D.T. Edizioni di Torino.

Marek, Dan H. (2007). Singing: the first art, Plymouth UK: The scarecrow press, inc.

Marek, Dan H. (2016). The Voice of Bel Canto, London: Rowman \& Littlefeld.

Menéndez Torrellas, G. (2013). Historia de la ópera, Tres Cantos: Ediciones Akal S.A.

Mieszkowski, S. (2014). Resonant Alterities: Sound, Desire and Anxiety in Non-Realist Fiction. Bielefeld: Transcript Verlag.

Radomski, J. (2000). Manuel García (1775-1832): Chronicle of the life of a Bel Canto Tenor at the Dawn of Romanticism, Oxford UK: Oxford University Press.

Rambotti, F. (2008). La musica è una mera opinione e di questa no si può dar certeza veruna, Perugia: Morlacchi Editore. 
Remondino, P.Ch. (1891). History of Circumcision from the Earliest Times to the Present: Moral and Physical Reasons for Its Performance, Philadelphia: BiblioLife.

Rendina, C. (2009). La santa casta della Chiesa - I peccati del Vaticano - l'oro del Vaticano, Roma: Newton Compton editori s.r.l.

Senelick, L. (2000). The changing room: sex, drag and theatre. London: Routledge.

Stark, J. (1999). Bel Canto: A History of Vocal Pedagogy, Canada: University of Toronto Press Incorporated. 